\begin{tabular}{lll}
\hline Sij & Studies in Humanities and & SHE \\
Education & (2020)1(1): $1-20$ \\
he@ @ sabapub.com & \\
ISSN: $2709-9563$ &
\end{tabular}

\title{
Adoption of Climate Smart Agricultural Practices among Small Scale Farmers of Kurfa Chele District, East Hararghe Zone, Oromia Region, Ethiopia.
}

\author{
Suleyman Abdureman Omer*, \\ Research Facilities Management, Institution of Haramaya University, Oromia Region, Ethiopia., \\ suleymanabdureman65@gmail.com \\ Nuradin Abdi Hassen \\ Rural Development and Agricultural Extension Department, Institution of Haramaya University, \\ Oromia Region, Ethiopia. \\ nuradinabdi203@gmail.com \\ Received: $15.09 .2020 \quad$ • Accepted/Published Online: 08.11.2020 • Final Version: 15.12 .2020
}

\begin{abstract}
:
Effective adaptation to climate change among small scale farmers is therefore of critical importance and is dependent on the adoption of climate-smart practices. However, studies have shown low adoption of climate-smart farming practices among small scale farmers world over, in East Hararghe Zone and Kurfa Chele District. This study, therefore, examined factors influencing adoption of climate-smart practices among farmers Kurfa Chele District, East Hararghe Zone, evaluated their existing knowledge, attitude and practice of these practices, assessed their perception of climate change, examined the extent of climate information dissemination, and the resultant impact on the uptake of these practices. The research adopted a survey research design, where both quantitative and qualitative research strategies were used. Data was gathered through Focus Group Discussions, questionnaires, key informant interviews, observations and a desk review. Both simple random and purposive sampling was used to sample 420 small scale farmers and technical officers of the agriculture sector respectively. Data were analysed using both quantitative and qualitative techniques. To test the statistical significance of the findings and relationships between the variables, the chi-square test was used.
\end{abstract}

Keywords: adoption: climate-smart practices; knowledge; attitude; practise; perception

\section{INTRODUCTION}

\subsection{1 Background of the Study}

The agriculture sector is vital in the eradication of extreme poverty and hunger and supports livelihoods of close to 1.5 billion people worldwide living in smallholder households in rural areas (World Bank, 2008). Despite its vital importance, the sector is highly sensitive

Corresponding author: Suleyman Abdureman Omer Email: suleymanabdureman65@gmail.com 
and susceptible to climate change and variability (Perret, 2006; Fischer et al., 2005; Van de Steeg et al., 2009; Schlenker \& Lobell, 2010), and small scale farmers are disproportionately affected, as a result of poverty, high dependency on natural resources and inadequate capability to adopt new livelihood strategies (Osbahr \& Viner, 2006).

Intergovernmental Panel on Climate Change (IPCC, 2007b) affirmed climate change occurrence and has projected further change and upsurge in the mean climate characteristics. This is likely to cause more severe effects on agriculture that has already registered instability in production, decreases in crop yield and livestock productivity. This will subsequently enhance hunger among millions of people worldwide, particularly in Latin America, Small Island States, Africa and some parts of Asia. This precarious situation is as a result of low adaptive capacity attributed to poor resource base, weak institutions and limited technology (IPCC, 2007a). Estimates of the impacts of climate change on agriculture suggest that in future, both productivity and production stability will decline in areas experiencing food insecurity (FAO, 2010). Over years, improved technologies including climate-smart practices have been developed and disseminated in Ethiopia, by Agricultural and Research Organization and through donor-supported programs and projects (MOALFD, 2010). In spite of the implementation of these programs, the adoption of climate-smart practices has remained low, particularly among small scale farmers (Ogada et al., 2014; Mugwe et al., 2009). Similarly, in response to effects of vagaries of weather attributed to climate change in Kurfa chele district, climate smart practices(henceforth CSPs) have been disseminated for several decades. In spite of these efforts, adoption of CSPs has also remained low among small scale farmers Agriculture Sector Development Support Programme (ASDSP, 2014).

\subsection{Statement of the Problem}

Climate change and variability have resulted in decline and instability in production worsening the existing food insecurity and poverty in developing countries. The effects of these climatic changes will become even more pronounced among small scale farmers, whose farming activities are weather dependent and vulnerable to climate change, and already adversely affected by environmental degradation and socio-economic risks (World Bank, 2008; Rao et al., 2011; Thornton et al., 2009; Van de Steeg et al., 2009; Schlenker et al., 2010). To ensure resilience, adoption of climate-smart practices among small scale farmers is required. Despite the vital role played by climate-smart practices in not only enhancing resilience, but also increasing productivity, reducing greenhouse gas emissions, and addressing environmental degradation, their adoption by small scale farmers has been low globally (FAO, 2010; FAO, 2013; Fanen et al., 2014). This is due to several lapses and challenges that have not been explored (Dance \& Sarpong, 2011; Roncoli et al., 2009; Adger et al., 2007). Most studies tend to focus on the impact of climate change on agriculture and adaptation measures (Mburu, 2013; Rao et al., 2011; Schlenker et al., 2010; Van de Steeg et al., 2009; Sivakumar et al., 2005), but few have examined the factors that affect the adoption of adaptation methods (Deressa et al., 2009). Agriculture in East and Central Africa contributes about $40 \%$ of the region's Gross Domestic Product (GDP) and is the main livelihood source for approximately $80 \%$ of the population in the region International Food Policy Research Institute (IFPRI, 2004). However, the high variability of rainfall both within and between seasons across the region has caused uncertainty and large fluctuations in farmers' yield and income. This has been compounded largely with a 
semi to arid conditions, degrading soils and high poverty (Fischer et al., 2005; IPCC, 2007a). The region undergoes protracted and extremely adverse droughts that cover expansive areas once every decade and more regular localized events (Christensen et al., 2007).

While farmers strive to adapt through innovation, studies by Rao et al., (2011) and Pettengell, (2010) indicated their limited capacity to effectively respond to these rapid and overwhelming changes beyond their normal experience. In response to these unpredictable changes in the agriculture sector and particularly among small scale farmers, several approaches have been suggested among them being "Climate Smart Agriculture". This is agriculture that sustainably enhances productivity, improves resilience, mitigates greenhouse gases, and boosts realization of national food security and development objectives (FAO, 2010; FAO, 2013).

This approach involves practices such as the adoption of climate tolerant varieties, risk insurance and use of climate information in farming. These practices are mainly aimed at both sustainability and agricultural intensification, considered key for ensuring enhanced productivity and food security.

This study, therefore, sought to identify factors that hinder the adoption of climate-smart practices among small scale farmers with specific focus to Kurfa Chele district.

\subsection{Objectives of the Study}

\section{General Objective}

To examine the factors influencing adoption of climate-smart practices among small scale farmers of Kurfa Chele district in the eastern Hararghe zone.

\section{Specific Objectives}

a) To analyze the perception of climate change risks, their effects on farming and influence on the adoption of climate-smart practices among small scale farmers of studies area.

b) To determine the existing knowledge, attitude and practice of climate-smart practices among small scale farmers of studies area.

c) To examine the extent of climate and weather information dissemination and its influence on the adoption of climate-smart practices among small scale farmers of studies area.

\subsection{Research Questions}

To achieve its objectives, the study was guided by the following research questions;

a)How is the perception of climatic change risks and their impacts on farming among small scale farmers influencing adoption of CSPs of studies area?

b)How are the existing knowledge and attitude towards influencing their adoption climate-smart practices among small scale farmers of studies area?

c)To what extent has climate information been disseminated and influence adoption of climate-smart practices among small scale farmers of studies area? 


\section{Research Methodology}

\subsection{Description of the Study Area}

Kurfa Chele woreda is one of the twenty-two woredas of East Hararghe zonal administrations in Oromia Regional State. It is located at a distance of $55 \mathrm{~km}$ from zonal town, Harar and $540 \mathrm{~km}$ from Addis Ababa. The woreda is bordered with Kersa woreda in the north, Haromaya and Fedis woredas in the east, Grawa and Bedeno woredas in the west and Grawa woreda in the south. The altitude of the woreda ranges from 1400 to 3400 meters above sea level Climate Smart Agriculture (CSA, 2010). The same source indicated that the woreda falls into high land, midland, and low land agro-climatic zones. The total area of the woreda is 30,177 ha (KWARDO, 2015) or 259.69 square kilometre (CSA, 2010). Of its total area, $36 \%$ is high land, $13 \%$ is midland and the remaining $51 \%$ is lowland. From the total coverage, 11,894.84-hectare is used for agricultural production, 6,746 hectares are covered by forest, 3817 hectares is used for grazing land, 2,905 hectare is arable land, and 4814.16 hectares is used for another purpose. Its annual average temperature varies between a maximum of $31 \mathrm{c} 0$ and a minimum of $10 \mathrm{c} 0$ with the annual rainfall ranges from $700 \mathrm{~mm}$ to $2000 \mathrm{~mm}$. The woreda has a total population of 58,712 in 2007, and it is projected to be 75,939 in 2016 given a $2.9 \%$ annual growth rate of Oromia Region. From this population 37,557 are females and 38,382 are males, 90.2\% of the total population lives in the rural parts of the woreda and the remaining $9.8 \%$ of the population are urban dwellers (CSA, 2007). More than $98 \%$ of the woreda population makes their livelihood on agricultural activities (KWARDO, 2015). The main crop items of the woreda are cereals mainly sorghum and maize, in small areas wheat and barley, cash crops khat and coffee in low land, Irish potato in high land and green pepper in some small low land areas but the size of farmland used for cash crop production is limited and their production system is rainfall dependent (KWARDO, 2015). Livestock keeping is also considered as subsidiary to the crop production activities. The same source indicated that Kurfa Chele has twenty kebele administrative. Out of these two of them are small urban kebeles while the remaining eighteen are rural kebeles. In each kebele Agricultural extension workers and Health extension workers were assigned by the woreda Agricultural and Health offices respectively. According to the information obtained from the woreda Rural Road Authority, 10 rural and 2 urban kebeles were accessible for all-weather roads while the remaining 8 rural kebeles were accessible only for dry season road. In the study area, agricultural production is largely rain-fed in the face of erratic rainfall and frequent drought. The mean land holding per farm household is $0.5 \mathrm{Ha}$ in general and even less for high land and irrigable low land areas (KWARDO, 2015).

\subsection{Study Design}

The research adopted a survey design involving both quantitative and qualitative research strategies. These research strategies facilitated the triangulation and dovetailing of the findings and helped to offset the weaknesses of either of the two approaches (Bryman, 2008).

\subsection{Sample Size and Sampling Procedure}


The sample size for the study was arrived at by use of a formula by Krejcie \& Morgan (1970). The formula entails determining the sample size(s), from a given fixed population(P) with the sample size within plus or minus 0.05 of the population proportion at a 95 percent level of confidence. The $95 \%$ confidence level is preferred because it is narrower, with lower variability and when coupled with a higher sample size it enhances precision (Bryman, 2008).

This formula is shown as follows:

$$
\mathrm{S}=\mathrm{X}^{2} \mathrm{NP}(1-\mathrm{P}) / \mathrm{d}^{2}(\mathrm{~N}-1)+\mathrm{X}^{2} \mathrm{P}(1-\mathrm{P})
$$

\section{Equation 2.1: Krejcie \& Morgan (1970)}

Where: $X 2=$ Chi-Square table value for 1 degree of freedom at the preferred confidence level (in this case 3.84), $N=$ the population size (336 149), $P=$ the population proportion (assumed to be 0.5), $d$ - the degree of precision stated as a proportion (0.05). use of the formula gave 384 as the minimum sample size for the study.

However, the study adopted a sample size of 420 participants who were randomly selected from each of the 15 wards in the study area. The sample size was larger to accommodate non-responses. Both probability and non-probability sampling techniques (simple random and purposive sampling) were used in this study. Simple random sampling technique was used in determining individuals for the administration of questionnaires. The population was divided into sampling units represented by wards. Proportional sample sizes for wards was arrived at using the following formula.

$n i=\mathrm{n} / \mathrm{N} * 420$

Where $\boldsymbol{n} \boldsymbol{i}$ is the sample size for the ward, $\mathbf{n}$ is the total number of farmers in the ward and $\mathbf{N}$ is the total number of farmers in the study area. The respondents were randomly sampled from lists of farmers, who had been assigned numbers. Purposive sampling was, on the other hand, used in identifying key informants and Focus Group Discussions (FGDs) participants. In this study key informant interviewees were individuals who had competence and knowledge in the area of Agriculture and climate change by their academic qualifications and or many years of work, drawn from public and private agencies. While focus group participants were mainly service providers (extension officers) and farmers who had working and farming experience in the area of study. They were also identified based on records of farmers and staff in the Agriculture and Livestock offices at the subcounty level.

\subsection{Data Collection Methods}

Before the actual data collection, pretesting of tools to determine their reliability and validity using a randomly selected sample of 30 farmers and technical officers of agriculture was conducted. The farmers and technical officers were drawn from all the three sub-counties of the study area. The study tools were considered reliable if the respondents answered the questions, in the same way, each time they were asked. The study tools were deemed valid, if they measured accurately the concepts; they were intended to measure (Bryman, 2008). The farmers and technical officers were taken through the questionnaire, key informant interview and focus group discussion tools and then asked to offer any 
suggestions and criticism regarding the clarity and appropriateness of each of the tools. After which, all of the recommendations and comments were taken into consideration and appropriate changes made (Bryman, 2008). Data collection commenced with administration of individual questionnaires to small scale farmers who had been randomly selected for the study, after which key informant interviews were carried out with technical officers of in the agriculture sector. Collection of data was undertaken by supervisors who consisted of 3 agricultural officers and 4 research assistants from each ward, who were trained and served with questionnaires.

\subsubsection{Questionnaires}

The questionnaires were administered to 420 farmers selected randomly for the study. The questionnaire items were aligned to the four themes of the study. The questionnaires captured data on demographic and socioeconomic profile of respondents, their perception about climate change, its effects on farming and corresponding responses, knowledge, attitude and adoption of CSPs among the respondents, factors perceived to influence adoption and the institutional and policy context of the adoption of climate-smart practices. The questionnaires also captured the extent of dissemination of climate information and its impact on the adoption of climate-smart practices.

\subsection{Focus Group Discussions}

Four mixed-sex Focus Group Discussions (FGDs) were undertaken, two with extension service providers from the agriculture sector, and the other two with farmers. These discussions involved small groups of eight to twelve people who were led through open discussion guided by a trained leader (skilled moderator). During the discussions, the leaders explained to the participants the purpose of the discussions. After which the discussions were structured around a checklist of carefully predetermined questions under the four themes of the study. Apart from ensuring full participation of every participant, further probing was undertaken to ensure sufficient information was generated. The proceedings of the discussions were noted on flip charts and note books.

\subsubsection{Key Informant Interviews}

Key informant interviews were conducted with a broad array of actors drawn from public and private agencies with specific mandate in agriculture or climate change adaptation. The key informant interviews were aimed at providing an in-depth understanding of climate change and its impacts in the study area, adoption of climate-smart practices, policies and institutional arrangement at the county level dealing with climate change challenges. These interviews were also aimed at determining the technical and institutional capacity to respond to changing climate and its effects. During the study, thirty key informants were interviewed.

\subsubsection{Observations}

Observations were made to confirm and gain primary knowledge of climate-smart technologies practiced in the study area. The observations were captured in field notebooks and in the form of pictures, and notes. 


\subsubsection{Desk Study}

To identify institutional and policy weaknesses concerning the adoption of CSPs in the study area, a desk study was undertaken. The desk review included analysis of existing policies, strategies and regulations in the agriculture, water, environment and land both at National and Country levels.

\subsection{Type of Data Collected}

Both primary and secondary data were collected to realize the objectives of the study.

The data was encapsulated in four themes as indicated below.

a) Existing knowledge, attitude and practice of CSPs among small scale farmers.

b) Perception of climate change, its effects on farming and its impact on adoption of CSPs among small scale farmers.

c) Extent of climate and weather information dissemination and its influence on adoption of CSPs among small scale farmers.

\subsection{6 Data Analysis}

Data were analysed by use of both qualitative and quantitative approaches. The quantitative data mainly questionnaire items were coded and analysed using SPSS version 16.0, where the generated results were presented in form of tables, charts and figures. Qualitative data from key informant interviews, FGD notes and desk review of policies was analysed by establishing the categories and themes, relationships/patterns and conclusions drawn in line with the study objectives (Gray, 2004).

Table 1. Data Analysis Matrix

\begin{tabular}{|c|c|c|c|c|}
\hline$\overline{\text { Objective }}$ & Data Sets & Data Source & $\begin{array}{l}\text { Analysis } \\
\text { Method }\end{array}$ & $\begin{array}{l}\text { Statisti } \\
\text { cal } \\
\text { Test }\end{array}$ \\
\hline 1 & $\begin{array}{l}\text { Knowledge, Attitude } \\
\text { and Practice of CSPs }\end{array}$ & $\begin{array}{c}\text { Questionnaires, Key } \\
\text { Informant Interviews, } \\
\text { Focus Group Discussions, } \\
\text { Field Observations }\end{array}$ & $\begin{array}{c}\text { SPSS, } \\
\text { Qualitative }\end{array}$ & $\begin{array}{l}\text { Chi- } \\
\text { square }\end{array}$ \\
\hline 2 & $\begin{array}{l}\text { Perception, Climate } \\
\text { Change and Its Effects, } \\
\text { Adoption of CSPs }\end{array}$ & $\begin{array}{c}\text { Questionnaires, Key } \\
\text { Informant Interviews, } \\
\text { Focus Group Discussions, } \\
\text { Field Observations }\end{array}$ & $\begin{array}{c}\text { SPSS, } \\
\text { Qualitative }\end{array}$ & $\begin{array}{l}\text { Chi- } \\
\text { square }\end{array}$ \\
\hline 3 & $\begin{array}{l}\text { Climate and Weather } \\
\text { Information } \\
\text { Dissemination Adoption } \\
\text { of CSPs }\end{array}$ & $\begin{array}{l}\text { Questionnaires, Key } \\
\text { Informant Interviews, } \\
\text { Focus Group Discussions, } \\
\text { Field Observations }\end{array}$ & $\begin{array}{c}\text { SPSS, } \\
\text { Qualitative }\end{array}$ & $\begin{array}{l}\text { Chi- } \\
\text { square }\end{array}$ \\
\hline
\end{tabular}




\section{Results And Discussion}

\subsection{Perception of Climate Change Effects on Farming and its Influence on adoption of CSPs}

The first objective of this study was to assess perception of climate change risks on farming among small scale farmers of the study area and its influence on adoption of CSPs.

\subsubsection{Perceived Climate Change}

Almost all respondents $(97.4 \%, \mathrm{n}=409)$ were in agreement that climate change was a reality. Similarly, majority $(63.1 \%, \mathrm{n}=265)$ felt strongly that climate change was evident in the study area. This showed clearly the growing awareness of climate change challenge among farmers in the study area.

These findings were in agreement with several studies that had shown increasing awareness of farmers with regard to climate variability and change in Kenya and other parts of East and Central Africa in both drier areas and humid areas (Oremo, 2013; Legesse et al., 2012; Mburu, 2013; Kalungu et al., 2013; Nyanga et al., 2011). Interviews with key informants, particularly service providers in the agriculture sector indicated growing realization of climate change predicament.

In spite of the emerging appreciation of climate change concern, there were still other farmers, who still held the belief that the area was humid with adequate rainfall from both long rain and short rain seasons according to FGDs. There is therefore need for further sensitization to affirm and deepen their grasp of the climate change problem in the study area. Similarly, in spite of the glaring observation, analysis of County Government documents clearly demonstrated that most County Government officials were still oblivious of and not concerned about climate change (KCG, 2014). This was evidenced by lack of clear policy guidelines on climate change adaptation in agriculture. This implies that there is need for enhanced efforts towards creation of awareness on the causes and risks associated with climate change among the policy makers at the Country level.

\subsection{1.2. Perceived and Actual effects of Climate Change on Farming Activities}

Farmers cited different effects both in general and with regard to different aspects of climate change such as temperature, rainfall, change in rainfall patterns, droughts and floods.

In terms of general effects of climate change, most $(81.9 \%, n=344)$ of the respondents indicated inability to plan their farming activities and decline in crop yields $(11.2 \%, \mathrm{n}=47)$ as the main effects of climate change. Other effects of climate change cited included livestock deaths (1.2\%); destruction of crops and insufficiency of pastures (1.7\%). This showed that farmers were mostly being affected by shift in seasonal and erratic weather patterns, as shown by difficulties they were experiencing in planning. The findings also implied some element of flooding and drought occurrence in the Study Area as evidenced 
by destruction of crops, livestock deaths and insufficiency of pastures though to a small extent.

This study further affirms the findings at Yatta in Kenya, in Africa and other parts of the world, which showed decline in agricultural production and enhanced food insecurity as a result of climate change (Mendelsohn et al., 2000a; Boko et al., 2007; Mburu et al., 2014: Oromo, 2013). Key informants similarly indicated negative effects of climate change such as increased food insecurity, as a result of decline in food production. Other effects mentioned by key informants included increased leaching of nutrients and soil erosion as a result of surface runoff, and emergency of diseases such as Maize Lethal Necrosis Disease (MLND), Mites on Eucalyptus, and Tuta absolute pest on tomatoes. With regard to effects of increase in temperature on farming, emergence of new strains of pests and diseases $(40.7 \%, \mathrm{n}=171)$, decline in crop yield $(24 \%, \mathrm{n}=101)$ and wilting of crops $(5.2 \%, \mathrm{n}=22)$ were the main effects which were cited. At the same time a significant number $(30 \%, n=126)$ of respondents showed unawareness with regard to the likely effects of temperature on farming activities (Table 3.1).

Table 2. Effects of Increased Temperature on Farming in the Study Area

\begin{tabular}{ccc}
\hline Effects of increased temperature on Farming & Frequency $(\mathrm{n})$ & Percentage $\%$ \\
\hline Emergence of new strains of pests and Diseases & 171 & 40.7 \\
Decline in crop yield & 101 & 24.0 \\
Wilting of crops & 22 & 5.2 \\
I don't know & 126 & 30 \\
Total & 420 & 100.0 \\
\hline
\end{tabular}

These results are consistent with IPCC report, which suggests that while temperate regions are likely to benefit in terms of crop yield as a result of increase in temperature, the tropical regions and semi-arid areas are likely to experience negative impacts such as decline in crop yield even with moderate rise in temperature of $1-2^{\circ} \mathrm{C}$. The report indicates possibility of all regions in the world experiencing negative impacts as a result of further upsurge in temperature by the end of $21^{\text {st }}$ Century (IPCC, 2007b). In terms of effects of increase in rainfall and floods on farming, results showed that majority $(58 \%, \mathrm{n}=242)$ of the farmers were not aware. Apparently flooding may not be common and hence low appreciation of its negative effects among the majority of farmers.

The effects, which were known to them as a result of increase in rainfall were soil erosion $(22 \%, \mathrm{n}=94)$ probably due to the fact that the area is hilly and prone to soil erosion.

Other effects were noted, however, to a very limited extent. Decline in crop yield, destruction of crops, poor quality pasture as result of nutrient leaching and pests and diseases scored very low respectively $(6 \%, \mathrm{n}=26),(4 \%, \mathrm{n}=18),(4 \%, \mathrm{n}=18),(3 \%, \mathrm{n}=13)$. These findings on the overall showed low effects of enhanced rainfall that is normally accompanied by flooding in other areas. This is because of the hilly nature of the topography of the study area. 
Compared to other climate change variables, the impact of irregular rainfall patterns was highly pronounced in the area. Almost all $(99.8 \%, \mathrm{n}=419)$ of the respondents underscored the negative effects of erratic rainfall patterns on farming. Majority $(70.5 \%, n=296)$ identified decline in crop yield as the most serious effect, followed by inability to plan farming activities $(23.8 \%, \mathrm{n}=100)$ and instability in production $(5.5 \%, \mathrm{n}=23)$ (Table 3.2).

Table 3. Effects of Erratic Rainfall Patterns on Farming in the Study Area

\begin{tabular}{ccc}
\hline Effects of erratic rainfall Patterns & Frequency(n) & Percentage\% \\
\hline Decline in crop yield & 296 & 70.5 \\
Inability to plan farming activities & 100 & 23.8 \\
Instability in production & 23 & 5.5 \\
No response & 1 & 0.2 \\
Total & 420 & 100.0 \\
\hline
\end{tabular}

These results were in agreement with Huho et al. (2012), who affirmed changing rainfall patterns in Laikipia County with overall decline in growing period of crops and yield. Similar results were also obtained by Arukulem et al. (2015) at Senetwo Location in West Pokot County, who indicated reduced growing period, erratic planting dates, and overall decline in yield as a result of changing rainfall pattern. This showed the need to provide timely weather information to farmers to help them plan and mitigate the effects of erratic rainfall patterns.

\subsubsection{Farmers Degree of Perception and Concern about Climate Change effects on Farming}

In agreement with the above findings, majority $(97.3 \%, \mathrm{n}=409)$ of farmers agreed that climate change had negatively affected their farming activities (Table 3.3). Similarly, (54\%, $\mathrm{n}=227$ ) strongly felt climate change had serious implications on farming enterprises (Table $3.3)$.

Table 4. Farmers Degree of Perception about Climate Change Effects on Farming in the Study Area

\begin{tabular}{ccc}
\hline Farmers degree of perception & Frequency(n) & Percentage\% \\
\hline Strongly agree & 227 & 54.0 \\
Agree & 182 & 43.3 \\
I don't know & 11 & 2.7 \\
Total & 420 & 100.0 \\
\hline
\end{tabular}

On the other hand, shows that most $(92 \%, \mathrm{n}=385)$ of farmers were concerned about climate change effects. Key informants attested to the concerns farmers had with regard to climate change that had been demonstrated by frequent visits of farmers seeking for information on adaptation to the changing conditions. These findings were in agreement with a study by Arbuckle et al. (2013) among Iowa farmers in the United States of America, who showed concern about climate change effects and pursuit of adaptation strategies to climate change. 
The high concern about climate change effects among farmers in the study area, therefore pointed to their serious need for adaptation hence adoption of CSPs.

\subsubsection{Adaptation to Climate Change effects}

Most $(74 \%, \mathrm{n}=311)$ of the respondents acknowledged efforts towards mitigation of climate change effects. This revealed considerable emphasis on adaptation to climate change effects in the study area among the majority farmers.

However, majority $(72.5 \%, \mathrm{n}=305)$ could only indicate adaptation to climate change through adoption of appropriate crop and livestock varieties. Very few farmers thought of diversification to other non-farming activities (1\%), increased water conservation (3\%), varying planting date (9\%) and insuring of crops and livestock (1\%) as adaptation measures to climate change.

These results showed farmers high consideration of planting and rearing suitable varieties as key measure of adaptation to climate change. However, they demonstrated limited understanding of many other adaptation options such as agroforestry, insurance, water conservation etc. The results were also in congruence with several studies (Deressa et al., 2009; Legesse et al. 2012) in Ethiopia, which showed adoption of suitable varieties as one of the key response strategies to climate change effects. This is also in agreement with IPCC (2007a) which considers adoption of appropriate varieties of crops and livestock feeds such as finger millets, sorghum, groundnuts and wonder grass as a key element in combating the threat of climate change to food security. Key informant interviews with technical officers of Agriculture, also affirmed shift towards CSPs such as greenhouse and water harvesting technologies in response to perceived climate change among farmers.

\subsection{2 Farmers Knowledge, Attitude and Practice of CSPs}

The second objective of this study was to determine the existing knowledge, attitude and practice of CSPs among small scale farmers of the Study Area. Adoption of agricultural innovations has been shown to depend on farmer's knowledge and attitude (Roger, 2003). It was therefore hypothesized that knowledge of CSPs among small scale farmers of the study area had significant influence on their adoption.

\subsubsection{Operational Knowledge of the CSPs}

Majority $(85 \%, \mathrm{n}=357)$ of the respondents indicated dearth of working knowledge with regard to these practices, only a few $(15 \%, \mathrm{n}=63)$ acknowledged possession of operational knowledge (Table 3.8).

Table 5. Operational Knowledge of CSPs among Small Scale Farmers in the Study Area

\begin{tabular}{ccc}
\hline Operational knowledge & Frequency $(\mathrm{n})$ & Percentage $\%$ \\
\hline Yes & 63 & 15.0 \\
No & 357 & 85.0 \\
Total & 420 & 100.0 \\
\hline
\end{tabular}


This showed the enormous ground yet to be covered in terms of enhancing knowledge levels among these farmers, in order to promote adoption of CSPs. FGDs and Key informant interviews with farmers and technical officers affirmed limited understanding of the concept of CSPs not only amongst farmers but also extension service providers. These findings are in agreement and affirm the outcomes of several studies (Ajayi et al., 2006; Sanginga \& Woomer, 2009; McCarthy et al., 2011; Blanco \& Lal, 2008), which indicated knowledge as a fundamental constraint to adoption of agroforestry practices, pasture management and rehabilitation, intercropping, soil and water conservation structures, cover crops and improved fallows.

These findings were in congruence with the lessons learnt from a 3 year Mitigation of Climate Change in Agriculture (MICCA) pilot project in Kaptumo, Nandi County of Kenya, which promoted adoption of CSPs such as agroforestry, improved fodder production, tree nurseries, manure management, composting and biogas generation (FAO, 2015). At the end of the project it was apparent adoption of the select CSPs was constrained by lack of knowledge (FAO, 2015).

\subsubsection{Perceived Level of Knowledge of CSPs among Farmers.}

Among respondents (15\%), who had indicated as having knowledge of CSPs, very few of them had high $(5.2 \%)$ to very high $(0.2 \%)$ knowledge levels, majority $(9.76 \%)$ had low knowledge level. According to key informants, the low level of knowledge was attributed to inadequate knowledge on the part of extension service agents with regard to CSPs, lack of training materials and opportunities for learning CSPs and lack of explicit policy for implementation of CSPs. This explicitly showed that low level and lack of knowledge on climate practices, was a key factor constraining the adoption of CSPs in the study area. This was in agreement to the findings by FAO (2015) in Nandi County, Kenya and Fanen et al. (2014) in Northern Nigeria.

\subsubsection{Attitude towards CSPs}

\subsubsection{Preference for CSPS}

Most (84.5\%) farmers expressed enormous preference for the practices. FGDs affirmed the positive attitude amongst farmers concerning CSPs. This implies most farmers were willing to apply the practices, but are constrained by other factors such as lack of finances. These findings were in contrast with those of Margues et al. (2015) in central Spain, who found that most $(68 \%)$ farmers were unwilling to use cover crops to control soil erosion. This revealed the negative attitude attributed to lack of knowhow.

\subsubsection{Reasons for Preferring CSPs}

Most (79.9\%) farmers considered CSPs favorably mainly because of their potential to contribute to increased income $(28.5 \%, \mathrm{n}=120)$, high productivity $(16.2 \%, \mathrm{n}=68)$, production $(24.5 \%, \mathrm{n}=104)$ and better planning of farming $(10.7 \%, \mathrm{n}=45)$ linked to use of agro weather information (Table 3.9). These results clearly showed that most farmers were more inclined to practices that enhanced income, productivity and production within the context of small land sizes in the study area. This affirmed the argument of Woelcke (2012) 
that farmers were more likely to adopt practices which contributed to increase in production and income.

Table 6. Reasons for Preference of CSPs in the study area

\begin{tabular}{ccc}
\hline Responses & Frequency $(\mathbf{n})$ & Percentage $\%$ \\
\hline Increases productivity & 68 & 16.2 \\
Improves soil fertility & 29 & 6.9 \\
Enhances resilience to climate & 11 & 2.6 \\
Change & & \\
Better planning of farm activities & 45 & 10.7 \\
Improves production & 104 & 24.8 \\
Increases income & 120 & 28.5 \\
Enhances food security & 16 & 3.8 \\
No preference & 27 & 6.4 \\
Total & 420 & 100.0 \\
\hline
\end{tabular}

\subsubsection{Risks and Uncertainties of Adopting CSPs}

Majority $(60.5 \%, \mathrm{n}=254)$ of the respondents, perceived adoption of CSPs as risky and uncertain, only $(39.5 \%, \mathrm{n}=166)$ viewed adoption of CSPs as posing either moderate or low risk at all (Table 3.10).

Table 7. Level of Risk of Adopting CSPs in the study area

\begin{tabular}{ccc}
\hline Level of risk of adopting CSPs & Frequency(n) & Percentage \% \\
\hline High & 254 & 60.5 \\
Moderate & 163 & 38.8 \\
Low & 3 & 0.7 \\
Total & 420 & 100 \\
\hline
\end{tabular}

This affirms the postulation that adoption of most innovations face uphill task in a population when it's first introduced, with only a few early adopters taking up the challenge because of risk averseness (Rogers, 2003). There were several perceived risks that respondents gave in relation to adoption of CSPs, however, high capital and labor requirement per unit area (61\%) and uncertain returns $(32.1 \%)$ featured prominently compared to others such season specificity of these technologies limiting economic benefit to certain type of seasons (6.9\%) (Table 3.11). This unequivocally shows high capital and labor requirement and uncertainty of returns constitutes the most serious risks that had hindered adoption of CSPs in the study area.

Table 8. Risks of adopting CSPs in the study area

\begin{tabular}{lll}
\hline Risks of adopting CSPs & Frequency(n) & Percentage\% \\
\hline Season specificity of these technologies & 29 & 6.9 \\
\hline
\end{tabular}




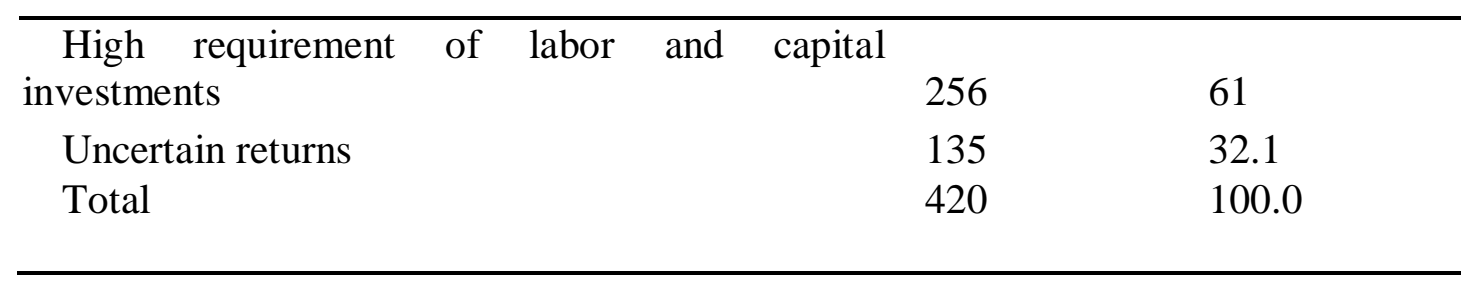

\subsubsection{Practice of CSPs}

Findings show that some $(65.7 \%, \mathrm{n}=276)$ farmers attempted to practice CSPs (Table 3.12). However, $36.8 \%$ of the farmers abandoned the practices for various reasons, and only few $(28.9 \%)$ continued with adoption of practices.

Table 9. Attempted Practice of CSPs in the study area

\begin{tabular}{lll}
$\begin{array}{l}\text { Attempted practice of } \\
\text { CSPs }\end{array}$ & Frequency & Percentage \\
& (n) & $\%$ \\
\hline Yes & 276 & 65.7 \\
No & 144 & 34.3 \\
\hline Total & 420 & 100.0 \\
\hline
\end{tabular}

This corroborates findings by Omoro (2014) who found that several farmers abandoned green house technology even after high initial capital investment in Kisii and Nyamira Counties due to low production and sometimes total failure of the crops. According to the same study, the poor performance was attributed to lack of knowledge and skill (Omoro, 2014).

\subsubsection{Policy Framework and Adoption of CSPs}

Analysis of National and country documents showed lack of sector specific climate risk management plans, due to limited or lack of awareness concerning climate change effects. Similarly, while there were provisions that support adoption of CSPs, they were inconsistent, weak and are faced with implementation and enforcement challenges. Similarly, regional government apparently doesn't seem to adhere to the provisions, because of weak national and county government linkage. During Focus Group Discussions, the agriculture sector service providers acknowledged existence of weak policies and poor implementation due to financial constraints. They contended that policies do not adequately address environmental concerns; they also indicated weak researchextension-farmers and regional- National government linkages. This is supported by Maina et al. (2013) who found that existing lack of policy coherence posed the risk of weakening long term policy goals on climate change and Agriculture. 


\subsection{5 Climate and Weather Information Dissemination and its Influence on Adoption of CSPs among Small Scale Farmers}

\subsubsection{Extent of Climate and Weather Information Dissemination in the study area}

Findings of this study revealed very low $(23.3 \%)$ access to weather and climate information disseminated in the form of agro weather advisories. Majority (76.7\%) of the respondents indicated they were oblivious of the information that included technical advises on appropriate practices undertaken to ensure resilience to climate and seasonal weather shocks.

This revealed the low extent of dissemination of agro weather advisories, and hence the high vulnerability among farmers to climate change risks in the study area. The low access was as a result of weak and limited dissemination of agro weather advisories (Key Informants and FGDs). These findings were consistent with Harvey et al. (2009), who expressed concern over inadequate sharing of climate information in Africa, which had led to limited access to climate information particularly among small scale farmers. These results were similar to the outcome of a survey conducted by Jha et al.( 2012) in Bundelkhand region of Central India which showed that farmers relied mostly on local and traditional sources of information to make their farming decisions. Only $15 \%$ of the respondents during the survey indicated access to agro meteorological information in this region of India. This affirms low access of agro meteorological information among farmers in developing countries, in spite of the high vulnerabilities to the vagaries of weather.

\subsubsection{Channels used in Dissemination of Agro Climate and Weather information to Farmers}

From the findings it was explicit, the main mode of communication that reached a wider audience among respondents with agro weather advisories was both electronic (TV, Radio) and print media (Newspapers) $(42 \%)$.

This revealed that the most effective way that agro weather information can be disseminated in the study area was through the media, particularly through the local vernacular FM radios, which have a wide audience among the rural farmers. This corroborates WMO (2009) and Weiss et al. (2000) assertion that television and radio remains the most reliable means of dissemination of agro weather information among small scale farmers, and particularly when broadcasted in the local languages.

Other ways through which agro weather information was provided to farmers included barazas (2\%), extension service (13\%), field days (3\%) and farmer groups (1\%) but to a very limited extent. Similarly, there was a significant portion $(39 \%)$ of farmers who were not accessible to any channel of dissemination. These results indicated significant shortcomings in dissemination of agro weather information through extension services and farmer organizations, which once strengthened would lead to enhanced access of agro weather information among farmers. These results were also in agreement with a study carried out by Zendera (2011) among smallholder farmers in Perkerra and Lari-Wendani Irrigation schemes in Kenya. The study revealed that $98 \%$ of the farmers received agro meteorological information through radio, but to a very limited extent through bulletins, mobile phone, internet, agricultural extension services and barazas. 


\subsubsection{Knowledge of application of Agro -Climate and Weather Information}

Only $11 \%$ of the respondents had the understanding on the working knowledge of agro weather information, while majority $(84 \%)$ indicated lack of knowledge. This is a sharp decline from the proportion that indicated awareness (23.3\%). This shows that even though some farmers have awareness, they lack the how and why knowledge with respect to agro weather advisories considered vital in influencing farmers decisions (Roger, 2003).

The low knowledge level was attributed to low access to climate information and lack of training on interpretation of the information in terms of management strategies to be undertaken according to key informants \& focus group discussions. This is in congruence with Chamboko et al. (2008), who found similar results in his study in Zimbabwe. As recourse participatory process involving farmers, traditional forecasters, extension service and meteorological services providers has been suggested (WMO, 2012) and is currently being promoted by ASDSP in all 47 counties. This approach referred to as Participatory Scenario Planning (PSP) ensures sharing and interpretation of weather and climate information for enhanced understanding and application by all agricultural stakeholders including farmers.

\subsubsection{Extent of Weather and Climate Information Dissemination and Adoption of CSPs}

Adoption of CSPs in response to weather and climate information revealed positive correlation. Apparently, adoption was low and ranged between (1.2\% to 21.9\%) (Table 4.58). The low adoption of practices was a consequence of limited access to the information among farmers. According to Deressa et al. (2009) availing climate information enhanced the adoption of appropriate crop varieties by $17.6 \%$ in the Nile basin of Ethiopia.

Findings similarly showed varying levels of adoption of climate practices in response to agro weather information. For instance some practices ranked highly among farmers compared to others i.e. use of organic manure (21.9\%), agroforestry $(19.28 \%)$, mixed cropping $(17.3 \%)$ and rain water harvesting $(17.1 \%)$ ranked relatively higher in terms of adoption. While adoption of index-based agricultural insurance (1.2\%), silage making $(2.14 \%)$, preservation of hay $(2.85 \%)$, improved fallowing $(3.3 \%, n=14)$ was quite low (Table 3.13). The difference was likely attributed to low awareness of practices such as index based insurance, limited livestock rearing and low awareness of climate change phenomenon among some farmers. This shows the need for simultaneous access of agro weather information with appropriate CSPs knowledge among farmers.

Table 10. Intensity of Adoption of CSPs in Response to Weather and Climate Information Dissemination in the study area.

\begin{tabular}{ccc} 
CSPs & \multicolumn{2}{c}{ Intensity of adoption } \\
\cline { 2 - 3 } & Frequenc & Percentage \\
& $\mathbf{y}(\mathbf{n})$ & $\%$ \\
Appropriate crop and livestock varieties & 54 & 12.85 \\
Mixed cropping & 73 & 17.3 \\
Integrated crop and livestock systems & 31 & 7.4 \\
Improved fallowing & 14 & 3.3 \\
Agroforestry & 81 & 19.28 \\
Green house technology & 24 & 5.71
\end{tabular}




$\begin{array}{ccc}\text { Intercropping with legumes and fertilizer fodder crops } & 59 & 14.04 \\ \text { Crop rotation } & 62 & 14.76 \\ \text { Rain water harvesting } & 72 & 17.14 \\ \text { Irrigation } & 26 & 6.2 \\ \text { Construction of water retention structures } & 59 & 14.05 \\ \text { Biogas production } & 14 & 3.3 \\ \text { Preservation of hay } & 12 & 2.85 \\ \text { Planting of cover crops } & 36 & 8.5 \\ \text { Pasture management e.g. controlled grazing, improved } & 23 & 5.48 \\ \text { forage varieties, deferment, Reseeding, control of weeds } & 9 & \\ \text { Silage making } & 92 & 2.14 \\ \text { Use of organic manure } & 5 & 1.9 \\ \text { Index-based agricultural insurance } & 21 & 5 \\ \text { Feed management to reduce methane emissions } & 33 & 7.85 \\ \text { Farm-specific nutrient management \& precise (micro- } & & \\ \text { dose) fertilizer application } & \end{array}$

\section{Conclusions and Recommendations}

\subsection{1 Conclusions}

Based on the findings of this study, the following conclusions were made; There was a growing awareness of climate change problem among small scale farmers and the emerging need for adaptation to climate change effects through the adoption of climate-smart practices. However, a significant proportion of farmers and district policymakers were still oblivious of the climate change challenge. Hence the limited focus on climate changes adaptation and adoption of climate-smart practices. There were significant knowledge gap and low practice of climate-smart practices, despite the positive outlook to climate-smart practices attributed to the collapse of extension services over the years and particularly after devolution of governance. Adoption of climate-smart practices was hampered mainly by dwindling farm sizes, limited knowledge of climate-smart practices, limited outreach of weather and climate information, low financial capability and weak policy framework. While these findings affirmed the importance of access to climate and weather information in enhancing the adoption of climate-smart practices. Its access and its use were low and patchy.

\subsection{Recommendations}

Based on the conclusions above, the study recommends the following;

The National Government and development partners to enhance sensitization of farmers and policymakers at the Region level regarding climate change and its impacts on agriculture.

The Ministry of Agriculture, Livestock and Fisheries at both National and the Country level of should undertake capacity building and strengthening of extension service delivery to enhance awareness, skill and knowledge for the adoption of climate-smart practices among farmers. The Ministry of Agriculture, Livestock and Fisheries at National and Country level to provide budgetary support and strengthen public-private partnership to leverage funds for the adoption of climate-smart practices. The Province Government should also set 
up the Climate Change Unit that will target carbon-related funds i.e. REDD+, Clean Development Mechanism (CDM), adaptation fund. The Ministry of Agriculture, Livestock and Fisheries to develop sound policy and legal framework for adoption of CSPs. The Ministry of Agriculture, Livestock and Fisheries at National and County level and Ethiopia Meteorological Services to upscale dissemination of climate information by packaging it into user-friendly formats and using channels that are effective and accessible to small scale farmers.

\section{References}

[1] Adger, W., Agrawala, S., Mirza, M., Conde, C., OBrien, K., Pulhin, J. (2007). Assessment of Adaptation Practices, Options, Constraints and Capacity. In C. O. Parry ML (Ed.), Climate change 2007: Impacts, Adaptation and Vulnerability.Contribution of Working Group 11 to the Fourth Assesment Report of the Intergovernmental Panel on Climate Change (pp. 717-743). Cambridge: Cambridge University Press.

[2] Arbuckle, Jr, J. G., Morton, L.W., \& Hobbs, J. (2013). Farmer Beliefs and Concerns about Climate Change and Attitude toward Adaptation and Mitigation: Evidence from Iowa. Climate change, 118 (3), 551-563.

[3] Arukulem, E.Y., Makindi, M.S., \& Obwoyere, G.O.(2015).Climate Variability and the Associated Impacts on Smallholder Agriculture in Senetwo Location, Kenya. International Journal of Science and Research(IJSR). 4(8), 845-850.

[4] Beddington, J., Asaduzzaman, M., Fernandez, A., Marrion G., Erda, L., et al. (2011). Achieving Food Security in the Face of Climate Change:Summary for Policy Makers from The Commission on Sustainable Agriculture and Climate Change. copenhagen, Denmark: CGIAR Research program on Climate Change, Agriculture and Food Security.

[5] Branca, B., Tennigkeit, T., Mann, W., \& Lipper, L. (2012). Identifying Opportunities for Climate-Smart Agriculture Investments in Africa". A study for FAO program of work on Economics and Policy Innovations for Climate-smart Agriculture (EPIC). , http://www.fao.org/climatechange/climatesmart/en/. Rome: FAO.

[6] Branca, G., McCarthy, L., \& JoleJole, M. (2011). Climate Smart Agriculture: A synthesis of Empirical Evidence of Food Security and Mitigation benefits from Improved Cropland Mnagement. Working Paper. Rome: FAO.

[7] Bryan, E., Ringler, C.,Okoba, B., Koo, J., Herrero, M.\& Silvia, S.(2013). Can Agriculture Support Climate Change Adaptation, Greenhouse Gas Mitigation and Rural Livelihoods? Insights from Kenya. Climatic Change, 118 (2),151-165.

[8] Bryan, E.,Ringler, C.,Okoba, B.,Roncoli,C.,Silvestri,Silvia.\& Herrero,M.(2011).Adapting Agriculture to Climate Change in Kenya: Household and Community Strategies and Determinants. Presented at George Washington University, Washington, D.C.,19 May 2011.

[9] CGIAR Center.

[10] CGIAR. (2009). Climate Change Agriculture and Food Security:A Strategy for Change.

[11] Chamboko, T., Mtambanemgwe, F., Chikowo, R., Mapfumo, P., \& Mekutia, M. (2008). Climate Change And Variability Information Access and Adaptation: The Case of Smallholder Farming Communities in Zimbabwe. pp. 110-115.

[12] Cherotich, K., Osen, I. S., \& Omedo, B. (2012). Access to Climate Change Information and Support Services by Vulnerable groups in Semi-Arid Kenya for Adaptive Capacity Development. African Crop Sciences Journal , 20(2), 169-180.

[13] Dooley, E., \& Chapman, S. (2014). Climate Smart Agriculture and REDD+ Implementation in Kenya. REDD+ Law Project-Briefing Paper

[14] Dulal, H., Brodnig, J., Onoriose, C., \& Thakur, H. (2010). Capitalising on Assets; Vulnerability and Adaptation to Climate Change in Nepal. World Bank Social Development Papers No, 121. 
[15] Fanen, T. (2014). Assesing the Role of Climate Smart Agriculture in Combating Climate Change, Desertification and Improving Rural Livelihood in Northern Nigeria . African Journal of Agricultural Research, 9(15), 1180-1191.

[16] FAO. (2010). Climate Smart Agriculture Policies, Practices and Financing for Food Security, Adaptation and Mitigation. United Nations. Rome Italy: Food and Agriculture Organisation.

[17] FAO. (2013). Climate Smart Agriculture Source Book. United Nations . Rome, Italy: Food and Agriculture Organisation.

[18] FAO. (2015). Smallholder Integrated Crop-Livestock Farming Systems: Scoping Study on Climate Smart Agriculture in Kenya. Mitigation of Climate change in Agriculture (MICCA) Programme. Background Report 8.Rome: FAO.

[19] FAO.(2015). Barriers, Incentives and Benefits in the adoption of Climate Smart Agriculture: Enhancing Agricultural Mitigation Within East Africa Dairy Development project(EADD) in Kenya. Rome: FAO.

[20] Fischer, G., Shah, M., Tubiello, F., \& Van Velhuizen, H. (2005). Socio-economic and Climate Change Impacts on Agriculture:An Intergrated Assesment,1990-2080. Philosophical Transaction Son Royal Society, 360 (1463), 2067-2083.

[21] Frank, J., \& Penrose Buckley, C. (2012). Small Scale farmers and Climate Change. How Can Farmer Organisations and Fairtrade built the Adaptive Capacity of Small Holders? IIED.

[22] Hallam, A., Bowden, A., \& Kasprzyk, K. (2012). Agriculture and Climate Change: Evidence on Influencing Evidence on Influencing Farmer Behavior. Scottish Government Social Research.

[23] Harvey, B., Diagne, B., Nnam, J., \& Tadege, A. (2009). Knowledge Sharing for Climate Change Adaptation in Africa: Opportunities and Challenges. Africa Adapt Guest Article,(73).

[24] Howden, S., Soussana, J., Tubiello, F., Chhetri, N., Dunlop, M., \& Meinke, H. (2007). Adapting Agriculture to Climate Change. Retrieved July 9, 2014, from http://www.pnas.org/content/104/50/19691.full.pdf+html.xii

[25] Howley, P., Cathal, O. D., \& Heanue, K. (2012). Factors Affecting Farmers Adoption of Agricultural Innovations:A Panel Data Analysis of the Use of Artificial Insemination among Dairy Farmers in Ireland. Journal of Agricultural Science, 4(6), 171-179.

[26] Ifejika, S. (2010). Resilient Adaptation to Climate Change in African Agriculture. Bonn, Germany: Deutsches Institut fur Entwicklungspolitik/German Development Institute.

[27] IFPRI.(2004).Ending Hunger in Africa: Prospects for the Small ScaleFarmer. International Food Policy Research Institute, Washington DC.

[28] IPCC. (2012). Managing the Risks of Extreme Events and Disasters to advance Climate Change Adaptation. A special Report of Working Groups I and II of the Intergovernmental Panel on Climate Change. In C. Field, T. Barros, D. Stocker, D. Qin, K. Dokken, M. Ebi, et al. (Ed.). Cambridge, UK and New York, NY, U.S.A: Cambridge University Press.

[29] IPCC. (2014). Impacts, Adaptation and Vulnerability. Contribution of Working Group II to the Fifth Assessment Report of the Intergovernmental Panel on Climate Change. Cambridge, UK: Cambridge University press.

[30] Kalungu, J. W., R, F. W., \& David, H. (2013). Small Holder Farmer Perception of the Impacts of Climate Change and Variability on Rainfed Agricultural Practices in Semi-Arid and Sub-humid Regions of Kenya. Journal of Environment and Earth Science, 3(7), 129-141.

[31] Kipkoech, K.A.,Tambi.E.,\& Bangali,S.(2015). State of Knowledge on CSA in Africa: Case studies from Ethiopia, Kenya and Uganda.The Forum for Agricultural Research in Africa, ACRA, Ghana.

[32] Kristin, E.D. (2004).Technology Dissemination among Small Scale Farmers in Meru Central District of Kenya: Impact of Group Participation. Ph.D. Dissertation Presented to the Graduate School of the University of Florida.

[33] Kubiszewski, I., \& Cleveland, C. (2012). United Nations Conference on Environment and Development (UNCED), Rio de Janeiro, Brazil. Retrieved July 20, 2014, from http://www.eoearth.org/view/article/156773

[34] Legesse, B., Ayele, Y., \& Bewket, W. (2012). Smallholder Farmers' Perceptions and Adaptation to Climate Variability and Climate Change in Doba District, West Hararghe, Ethiopia. Asian Journal of Empirical Research, 3(3), 251-265. 
[35] Maina, I;Newshan, A; Okoti, M.(2013). Agriculture and Climate Change in Kenya: Climate Chaos, Policy Dilemmas. Working Paper 07 .Agriculture Futures.Org.

[36] Marques, J.M.,Bienes, R.,Cuadrado, J.,Ruiz-Colmenero,M.,Barbero-Sierra, C.\& Velasco, A.(2015). Analysing Perceptions Attitudes and Responses of Wine growers about Sustainable Land Management in Central Spain. Land Degradation \& Degradation. 26(5), 458-467.

[37] Mburu, B., Muriuki, J., \& Kungu, J. (2014). Effects of Climate variability and Change on Household Food Sufficiency among Small Scale Farmers of Yatta District, Kenya. Journal of Environment, 3(2), 19-27.

[38] Mburu, B.K., Kungu, J.B. (2015). Climate Change Adaptation Strategies by Small -Scale Farmers in Yatta District, Kenya. African Journal of Environmental Science and Technology, 9(9), 712-722.

[39] Mburu, K. (2013). Effects of Climate Variability and Change on Dry land Agriculture and the Adaptation strategies by Small Scale Farmers in Yata District. PhD Thesis. Kenyatta University.

[40] McCarthy, N., Lipper, L. \& Branca G. (2011). Climate Smart Agriculture: Smallholder Adoption and Implications for climate change Adaptation and Mitigation. Mitigation of Climate change in Agriculture (MICCA) Programme, FAO. Rome.

[41] McCarthy, N., Winters, P., Linares, \& Essam, T. (2012). Indicators to Assess the Effectiveness of Climate Change Projects:Impact-Evaluation Guideliness. Inter-American Development Bank.

[42] Mendelsohn, R., A.Dinar, \& A.Dalfelt. (2000b). Climate Change Impacts on African Agriculture. Preliminary Analysis prepared for the World Bank. Washington, District of Columbia.

[43] Mendelsohn, R., W.Morrison, M.E.Schlesinger, \& N.G.Androva. (2000a). Country-Specific Market Impacts from Climate Change. Climatic Change, 45(3-4), 553-569.

[44] MENR. (2010). National Climate Change Response Strategy. Nairobi: Ministry of Environment and Natural Resources.

[45] MENR. (2013). National Climate Change Action Plan (2013-2017. Nairobi: Ministry of Environment and Natural resources. 